\title{
Evaluation of aggregate microstructures following natural regeneration in bauxite residue as characterized by synchrotron-based $\mathrm{X}$-ray micro-computed tomography
}

by Zhu, F., Liao, J., Xue, S., Hartley, W. Zou, Q. and $\mathrm{Wu}, \mathrm{H}$.

Copyright, Publisher and Additional Information: This is the author accepted manuscript. The final published version (version of record) is available online via Elsevier Please refer to any applicable terms of use of the publisher.

DOI: 10.1016/j.scitotenv.2016.08.10

Harper Adams

University 


\title{
Evaluation of aggregate microstructures following natural
} regeneration in bauxite residue as characterized by

\author{
synchrotron-based X-ray micro-computed tomography \\ Feng Zhu ${ }^{1,2}$, Jiaxin Liao ${ }^{1}$, Shengguo Xue ${ }^{1,2, *}$, William Hartley ${ }^{3}$, Qi Zou ${ }^{1}$, Hao Wu ${ }^{1}$ \\ 1 School of Metallurgy and Environment, Central South University, Changsha 410083, PR China \\ 2 Chinese National Engineering Research Center for Control and Treatment of Heavy Metal Pollution, Central South University, \\ Changsha 410083, China \\ 3 Crop and Environment Sciences Department, Harper Adams University, Newport, Shropshire, TF10 8NB, United Kingdom
}

\begin{abstract}
Bauxite residue often has poor physical conditions which impede plant growth. Native plant encroachment on a bauxite residue disposal area in Central China reveals that natural regeneration may improve its physicochemical properties. Residue samples collected from three different disposal ages were assessed to evaluate residue micromorphology and three-dimensional (3D) aggregate microstructure under natural regeneration. The residue aggregates in different disposal ages were divided in two sections: macro-aggregate $(2-1 \mathrm{~mm})$ and micro-aggregate $(0.25-0.05 \mathrm{~mm})$. Residue aggregate micromorphology was determined by scanning electron microscope and energy dispersive $\mathrm{X}$-ray spectroscopy, and the residue aggregate microstructure was determined by synchrotron-based $\mathrm{X}$-ray micro-computed tomography $(\mathrm{SR}-\mu \mathrm{CT})$ and image analysis techniques. Natural regeneration may improve residue aggregate stability and form a stable aggregate structure. Calcium content increased whilst sodium content decreased significantly on the surface of residue aggregates. Under natural soil-forming processes bauxite residue porosity, specific surface area, average length of paths, and average tortuosity of paths all significantly increased. This demonstrated that natural regeneration may stimulate the formation of stable aggregate structure in residues. Further understanding should focus on particle interaction forces and agglomeration mechanisms with the addition of external ameliorations.
\end{abstract}

\section{Highlights}

1. Physicochemical properties improved over time due to weathering.

2. Weathering stimulated the formation of stable aggregate structures in residues.

3. Weathering changed aggregate microstructures, including pore throat and shape parameters.

\section{Keywords:}

Bauxite residue; soil-forming processes; micro-computed tomography; aggregate microstructure; pore-throat network

\footnotetext{
* Corresponding author.

E-mail address: sgxue70@hotmail.com; sgxue@csu.edu.cn (Shengguo Xue)
} 


\section{Introduction}

Management and disposal of solid waste discharge from the non-ferrous metal refining process is a global environmental concern (Wu et al., 2016). Bauxite residue, a highly alkaline by-product, is generated when alumina is extracted from bauxite ores by the Bayer process (Kaur et al., 2016). Although many efforts have been made to utilize bauxite residue, few of them are commercially applied (Liu et al., 2014). Compared to marine disposal or lagooning, large volumes of bauxite residue are discharged to disposal areas using the dry-stacking method in which the residue slurry is thickened to a paste with a liquid-solid ratio of approximately 1.0 and then pumped to the stacking areas (Power et al., 2011). The global inventory of bauxite residue currently stored in such impoundments is estimated to be more than 3.4 billion tons, with an annual growth rate of approximately 120 million tons (Xue et al., 2016). Bauxite residue has high alkalinity, salinity and fine-grained particulates which create a series of environmental and ecological pollution issues (Renforth et al., 2012; Gelencsér et al., 2011). Safe and effective disposal of this solid waste is one of the critical ecological issues to sustainable development of the alumina industry. Weathering and subsequent revegetation of the residue converts it to a soil-like medium which is now regarded as the most promising method to ecologically manage this waste material (Jones and Haynes, 2011).

Significant challenges including elevated $\mathrm{pH}(10-12)$, salinity $(30-60 \mathrm{dS} / \mathrm{m})$ and exchangeable sodium percentage (50-90\%), combined with low organic carbon and reduced concentrations of potentially plant-available $\mathrm{N}, \mathrm{P}, \mathrm{K}, \mathrm{Ca}, \mathrm{Mg}, \mathrm{Mn}, \mathrm{Cu}$ and $\mathrm{Zn}$, limit sustainable plant cover establishment at the disposal areas (Jones and Haynes, 2011). Furthermore, poor physical conditions are one of the major limitations to revegetation as elevated sodium $(\mathrm{Na})$ and its fine structure deteriorate its ability to sustainably support vegetation (Ruyters et al., 2011). A number of strategies have been used to improve revegetation including soil capping, field neutralization, and incorporation of amendments, whilst plants species including Holcus lanatus, Festuca rubra and Acacia nilotica have been selected to grow on the disposal areas (Xue et al., 2016). Gypsum and organic matter are regarded as appropriate ameliorants as gypsum is a slightly soluble salt which provides calcium and decreases alkalinity, whilst organic matter will provide organic carbon, plant nutrients and stimulate microbial activity (Courtney and Kirwan, 2012; Chauhan and Ganguly, 2011). Although the addition of amendments may ameliorate the adverse physicochemical properties of bauxite residue, it is now recognized that for successful ecosystem establishment, soil formation and development are crucial to the rehabilitation process (Biederman et al., 2008). Several physical indicators, such as bulk density, porosity, aggregate size distribution and aggregate stability are widely used in order to evaluate the physical quality of mine residues (Asensio et al., 2013). Courtney et al. (2009) found that the addition of spent mushroom compost and gypsum affected residue $\mathrm{pH}$, EC and salinity, which positively impacted on residue microaggregate stability, preventing clay dispersion. Courtney et al. (2013) selected bulk density, porosity and water stable aggregates to assess soil formation in restored bauxite residue and found that the combined addition of gypsum and organic fertilizer increased aggregate stability and stimulated soil formation. Zhu et al. (2016) discovered that natural weathering processes may increase porosity and promote aggregate stability. However, little attention on aggregate microstructure has been considered (Gräfe and Klauber, 2011).

Soil aggregation and its stability influence carbon stabilization, water infiltration, nutrient transport, and the ability to resist water retention (Cheng et al., 2015). Aggregate size distribution and stability, and the size of pore spaces between and inside soil aggregates, indicate soil physical structure 
(Annabi et al., 2011). A detailed understanding of aggregate microstructure can provide information on soil aggregation processes. Recently, computed tomography (CT) has been introduced to explore 3D soil aggregate structure which is more visual and accurate than the $2 \mathrm{D}$ digital images of soil thin sections (Udawatta et al., 2008). Ma et al. (2015) used synchrotron-based X-ray micro-computed tomography to evaluate soil aggregate microstructure and stability under wetting and drying cycles and provided insights for improving our understanding of the changes in soil microstructure.

Under natural weathering processes, bauxite residue has been converted to a soil-like medium to support plant growth, whilst aggregate structure and aggregate stability of bauxite residue have been improved (Zhu et al., 2016). The hypothesis of this research is that natural regeneration may improve residue aggregation which can lead to significant differences in morphology and microstructure of residue aggregates. The objectives of this study were to 1) investigate residue aggregate morphology and the variation of elements on the surface of residue aggregates and 2) quantify the 3D microstructure of residue aggregates to evaluate the effects of natural regeneration on particle aggregation in bauxite residues.

\section{Materials and methods}

\subsection{Site description and residue sampling}

A bauxite residue disposal area in Central China $\left(35^{\circ} 24^{\prime} \mathrm{N}, 113^{\circ} 25^{\prime} \mathrm{E}\right)$ was selected as the study site as it has naturally weathered without human disturbance. It is located in a warm temperate continental monsoon climate characterized by four seasons and having a mean annual daily temperature of $13^{\circ} \mathrm{C}-15^{\circ} \mathrm{C}$. Long-term average annual rainfall ranges from $600 \mathrm{~mm}$ to $1200 \mathrm{~mm}$. More than $75 \%$ of precipitation occurs from June to September. Native vegetation has spontaneously encroached upon several areas of the disposal area.

Bauxite residue samples from three different locations related to disposal age were studied. These included (a) 1-year-old bauxite residue (Z1), (b) 10-year-old bauxite residue (Z2), and (c) 20-year-old bauxite residue with spontaneous native grass growing on it (Z3). All locations were sampled during August to September in 2014. The residues of depth 0-20 cm were sampled at three randomly chosen points at each location (a-c). Undisturbed bulk samples were stored in polyethylene bags, air dried in the laboratory at room temperature for two weeks and subsequently passed through a $2 \mathrm{~mm}$ sieve prior to analysis.

\subsection{Physical and chemical analysis}

Mechanical composition of bauxite residue was determined with a Malvern Mastersizer 2000 (Malvern Instruments Ltd., UK) (Santini and Fey, 2013). The pH and EC (electrical conductivity) of the residue samples were measured in water (ratio of solid:water 1:5) (Johnston et al., 2010). Exchangeable $\mathrm{Ca}^{2+}, \mathrm{Mg}^{2+}, \mathrm{K}^{+}, \mathrm{Na}^{+}$were determined by a method of extraction with $1 \mathrm{M}$ ammonium acetate $(\mathrm{pH}=7)$ and analyzed by inductively coupled plasma atomic emission spectroscopy (ICP-AES) (Zhu et al., 2016). Exchangeable sodium percentage (ESP) was calculated by the percentage of exchangeable sodium content in total exchangeable bases $(\mathrm{Ca}, \mathrm{Mg}, \mathrm{K}, \mathrm{Na}$ ). Total organic carbon (TOC) was measured by the dry burning method (Yilmaz, 2014).

\subsection{Residue aggregate stability analysis}

Aggregate stability of the residue was determined by sieving $50 \mathrm{~g}$ of $<2 \mathrm{~mm}$ samples through sieves of 1, 0.25 and $0.05 \mathrm{~mm}$ with a 34 stroke frequency for $3 \mathrm{~min}$ in distilled water (Karami et al., 
2012). Each aggregate fraction was dried at $75^{\circ} \mathrm{C}$ prior to weighing. The mean weight diameter (MWD) of each sample by wet sieving were calculated as $\sum_{\mathrm{i}=1}^{\mathrm{n}} \overline{\mathrm{X}_{\mathrm{i}}} \times \mathrm{W}_{\mathrm{i}}$, where $\overline{X_{\mathrm{i}}}$ was the mean diameter of size fraction $(\mathrm{mm})$ and $W_{\mathrm{i}}$ is the proportion of aggregates in that size range.

\subsection{Residue morphological analysis}

The residue aggregates in three different locations $(\mathrm{Z} 1, \mathrm{Z} 2$, and $\mathrm{Z} 3)$ had been separated into two sections: macroaggregates $(2-1 \mathrm{~mm})$ and microaggregates $(0.25-0.05 \mathrm{~mm})$. Micro-morphological studies of the residue fractions were carried out using a scanning electron microscope, equipped with energy dispersive X-ray spectroscopy (ESEM, Quanta-200) (Newson et al., 2006). The specimen was sputter coated with a layer of gold prior to examination.

\subsection{CT scanning and image processing}

Residue aggregates were scanned with a synchrotron-based $\mu$-CT, beam line BL13W1 (Shanghai Synchrotron Radiation Facility (SSRF)). Aggregates were fixed in a plastic tube mounted on a rotary stage which as rotated from $0^{\circ}$ to $180^{\circ}$ with a same step interval of approximately $0.1^{\circ}$. Samples were scanned with the SR- $\mu \mathrm{CT}$ at a photon energy of $19.5 \mathrm{keV}$. Reconstructed image slices from the radiographs used a filtered back-projection algorithm. A total of 1000 slices with a size of $1200 * 1000$ pixels for each slice were reconstructed for each aggregate.

ImageJ 1.48 was used to create images, visualization, and quantification of the obtained slices. Image segmentation by ImageJ removed obvious ring artifacts (Zhou et al., 2013). Images were firstly transformed from Cartesian space into polar space (Polar transformer plugin). To avoid edge effects, a volume of 300*300*300 voxels was extracted from the 3D aggregates (Schmid et al., 2010).

In this study, as has been successfully used in evaluating soil microstructure, the indicator kriging method was used for image segmentation and pore space geometry which were determined with 3DMA-rock software (Zhou et al., 2012). Voxels $(300 \times 300 \times 300)$ were cropped from the central part of each image. In order to reduce light variation among images, the stacked images were normalized using ImageJ before segmentation. Residue pores from the solid phase were extracted using the indicator kriging method (Oh and Lindquist, 1999). 3DMA-rock was used to analyze the pore space geometry and quantify 3D microstructure of residue aggregates (Lindquist et al., 2000).

\subsection{Data analysis}

All data was analyzed in Excel 2003 and SPSS 19.0. Paired sample t-test analysis (95\% confidence interval) was carried out to determine the residue samples with different disposal ages. ImageJ and 3DMA-rock were used to analyze the images and pore microstructure. All of the figures were constructed by Origin 8.0.

\section{Results}

\subsection{Bauxite residue properties}

With increasing disposal age, the proportion of sand significantly increased, whilst the proportions of silt and clay decreased which may due to the changes in disposal practice (Table 1). Natural weathering processes decreased the salinity and $\mathrm{pH}$ of stored residues. With increasing disposal age, $\mathrm{pH}$ decreased from 10.98 to 9.45 and the value of EC significantly decreased from 3.73 to $0.36 \mathrm{mS} / \mathrm{cm}$. 
Organic carbon content increased from $5.71 \mathrm{~g} / \mathrm{kg}$ to $10.81 \mathrm{~g} / \mathrm{kg}$. Mean weight diameter (MWD) ranged from $0.24 \mathrm{~mm}$ to $0.52 \mathrm{~mm}$ which indicated that under natural vegetation encroachment, not only chemical properties, but also physical conditions of the residue improved.

\subsection{Residue micromorphology}

Residue aggregate (2-1 mm) SEM images following natural regeneration are shown in Fig. 1. The newly stacked residue macroaggregates (Z1) had a sheet-like structure with many fine fragments. The aggregate surface was coarse leading to a comparatively loose structure. Residue aggregates stacked for 20 years (Z3) had a dense structure and granular particles were distributed uniformly. With increasing disposal age, aggregate structure appears to improve and become more stable in the bauxite residue. Calcium and sodium contents varied significantly following natural weathering processes. The total calcium content increased from $3.34 \%$ to $16.74 \%$, whilst the total sodium content decreased from $10.05 \%$ to $1.42 \%$ (Figure 1) which was consistent with the results of exchangeable calcium and sodium.

According to ESEM images and following natural regeneration processes, the $0.25-0.05 \mathrm{~mm}$ size fraction increased in size, the number of pores between microaggregates decreased, surface particle distribution became uniform and microaggregate structure varied from loose to dense (Fig. 2). The change in microaggregate surface $\mathrm{Ca}$ and $\mathrm{Na}$ contents was similar to macroaggregates. Calcium content increased from $7.62 \%$ to $20.69 \%$, whilst Na content decreased from $9.33 \%$ to $1.02 \%$. Furthermore, Ca content in microaggregate surfaces was greater than in macroaggregate surfaces.

\subsection{Visualization of soil aggregates}

The sanned macro- and microaggregates from the three different locations are shown in Fig. 3. Pores within the macro- or micro-aggregates were visually classified as inter- or intra-sub-aggregate pores based on pore positions. In three different residue samples, inter-sub-aggregate pores included channels and vughs. The residues which were stacked for the longest had larger channels and vughs. Intra-sub-aggregate pores were dominant in $\mathrm{Z3}$, suggesting a more porous sub-aggregate structure to support plant growth as compared to $\mathrm{Z} 1$ and $\mathrm{Z} 2$. An overall perspective of the pore structure in residue aggregates could be speculated from the 3D images of the pore systems (Fig. 3). The pore system of Z3 was more continuous than in Z1 and Z2. As for microaggregates (Fig. 4), with increasing disposal age, the diversity of intra-aggregate pores was not so obvious, whilst inter-aggregate pores increased. 3D structure of the residue microaggregates shows this result visually (Fig. 4).

\subsection{Porosity and pore-size distribution}

General quantitative information about the 3D pore system and pore throat networks within residue aggregates from different disposal ages is presented in Table 2. Total porosity showed statistically significant differences between residue macroaggregates and microaggregates under natural regeneration $(P<0.05)$. Macroporosity for macroaggregates and microaggregates of $\mathrm{Z3}$ was significantly higher than for the residues which had been stacked for less than 10 years $(P<0.05)$. Boundary and interior pores in the residue aggregates were pores which connected or did not connect to the outside of the whole volume respectively. The numbers of interior pores, boundary pores and total pores for $\mathrm{Z} 3$ were all less than for $\mathrm{Z} 1$ and $\mathrm{Z} 2(P<0.05)$, whilst the fractions of interior and boundary pores for the three different residues were significantly different $(P<0.05)$. 
Nodal pore size distribution showed that $\mathrm{Z} 3$ had the largest porosity within each pore size diameter (Fig.5). Macro- and microaggregates in residues exhibited the same trend which indicated that natural regeneration may increase the porosity of residue aggregates. The residue macroaggregates had the greatest porosity within the $200-300 \mu \mathrm{m}$ range, whilst residue microaggregates had the greatest porosity within the $100-300 \mu \mathrm{m}$ range.

\subsection{Path length}

Path length showed the quantitive distance between the centers of any two adjacent nodal pores in residue aggregates. Path lengths ranged from 6 to 721,7 to 658 and 6 to $576 \mu \mathrm{m}$ in macroaggregates with increasing disposal age (Z1 -Z3). In microaggregates the path lengths ranged from 8 to 613,6 to 581 and 8 to $706 \mu \mathrm{m}$ for Z1, Z2 and Z3 respectively. Significant differences in path lengths were observed among the residues. Compared to $\mathrm{Z} 1$ and $\mathrm{Z} 2$, residue aggregates (both macroaggregate and microaggregate) having been disposed for 20 years had a lower number of paths, but a higher average length of paths. With increasing disposal age, the average length of paths in aggregates increased significantly.

\subsection{Path tortuosity}

Following natural regeneration, the average tortuosity of paths increased significantly from 1.85 to 2.03 in macroaggregates, and varied from 1.90 to 2.02 in microaggregates (Table 2). The relative frequency of path tortuosity increased with increasing tortuosity up to 1.7-2.0, and then decreased with increasing tortuosity (Fig. 6). The relative frenquencies in Z3 were lower than in $\mathrm{Z} 1$ and $\mathrm{Z} 2$, in both macro- and microaggregates. The maximum tortuosity values were 2.6, 2.9, 3.4 for residue macroaggregates with increasing disposal age respectively, whilst for the residue microaggregates, the maximum tortuosity values were $2.8,3.1,3.5$ respectively.

\subsection{Pore throats}

Except for pore size and path tortuosity, throats of inconnected pores is another indicator to affect fluid flowing within the pore system. Throats of the pore system in residue aggregates were extracted to separate the interconnected pores, and their surface areas were calculated (Fig. 7). For 20 year old residue (Z3), the total number of pore throats was significantly lower than for Z1 and Z2 (Table 2). Compared to path tortuosity, the pore surface area distribution in aggregates showed the same trend. For macroaggregates, the largest throat surface areas in $\mathrm{Z} 1$ and $\mathrm{Z} 2$ were $9.21 * 10^{-3} \mathrm{~mm}^{2}$, and $7.86^{*} 10^{-3}$ $\mathrm{mm}^{2}$ respectively, whilst the largest throat surface area in $\mathrm{Z} 3$ was $0.01 \mathrm{~mm}^{2}$. For microaggregates, the largest throat surface areas in $\mathrm{Z} 1$ and $\mathrm{Z} 2$ were $4.97 * 10^{-3} \mathrm{~mm}^{2}$ and $7.13 * 10^{-3} \mathrm{~mm}^{2}$ respectively, whilst the largest throat surface area in $\mathrm{Z} 3$ was $0.01 \mathrm{~mm}^{2}$.

\section{Discussion}

\subsection{Effects on residue aggregation and aggregate micromorphology}

The relative rates of natural weathering processes and improvement in residue properties will influence soil-formation at the disposal area. Rainfall leaching will dissolve soluble alkaline minerals such as sodalite and calcite which will buffer pH and salinity (Santini and Fey, 2013), whereas wind erosion will affect the redistribution of aggregate sizes at the residue surface (Amézketa, 1999). Following natural regeneration, residue particles became coarser, $\mathrm{pH}$ and $\mathrm{EC}$ decreased, and with improving physicochemical properties, a more agreeable environment for microorganism and 
herbaceous plant colonization developed, as evidenced by the encroachment of plants on residues which had been stacked for 20 years. Microorganism activity binds clay with polysaccharides in microaggregates which thus improve particle aggregation (John et al., 2005). Plant roots are also considered as temporary binding agents which may affect soil aggregation (Bronick and Lal, 2005). With no external organic carbon additions, major sources in bauxite residue may be due to microbial activity and pioneer plant tissues (Bradshaw, 2000). Gräfe and Klauber (2011) suggested that in order to support the development of ecosystems on disposal areas, residue $\mathrm{pH}$ should be between 5.5 - 9.0, $\mathrm{EC}$ reduced to $<4 \mathrm{mS} / \mathrm{cm}$, whilst ESP should be less than $9.5 \%$. Weathering had therefore ameliorated the residues to the extent that it was now capable of supporting plant growth. The residues in $\mathrm{Z3}$ had a low EC $(0.36 \mathrm{mS} / \mathrm{cm})$ which was lower than $4 \mathrm{mS} / \mathrm{cm}$. Nevertheless residue $\mathrm{pH}(9.45)$ and ESP (28.99\%) were higher than the suggested rehabilitation objectives and a vegetation cover still established. Introduction of appropriate halophytes and alkaliphilic microbes may be selected to stimulate aggregation. Halophytes for example will exude organic acids, provide $\mathrm{H}^{+}$, increase the partial pressure of $\mathrm{CO}_{2}$ in rooting zones and stimulate microbial communities. Microbial activity may further reduce $\mathrm{pH}$ and remove excess $\mathrm{Na}^{+}$(Xue et al., 2016). Establishment of pioneer plant communities may further support the improvement of residue properties to encourage establishment of sustainable ecosystems on disposal areas.

Mechanisms of soil aggregation involve a variety of interactions with binding agents, including organic carbon and polyvalent ions (Six and Paustian, 2014). Accumulation of organic carbon and exchangeable $\mathrm{Ca}$ content were beneficial to aggregate stability in bauxite residue as organic carbon and $\mathrm{Ca}$ were effective binding agents in particle aggregation (Courtney et al. 2009; Courtney et al., 2013). According to residue micromorphology, aggregate size became coarser following natural regeneration. The dynamic changes of $\mathrm{Ca}$ and $\mathrm{Na}$ contents on the surface of the aggregates by energy-dispersive $\mathrm{X}$-ray analysis showed that the increase in Ca content had a positive correlation with the improvement of aggregate structure in the residues. Polyvalent ions such as $\mathrm{Ca}^{2+}$ may have bridged clay particles and organic carbon to enhance particle aggregation, or $\mathrm{Ca}^{2+}$ carbonates may precipitate to form secondary carbonate coatings which may bind primary particles together to inhibit clay dispersion (Jiang et al., 2012). Compared to macroaggregates, a higher $\mathrm{Ca}$ content existed on the surface of microaggregates which verified the hierarchical order of particle aggregation: the lowest hierarchical order was the formation of microaggregates, including clay particles, organic molecules (OM) and polyvalent cations (P) (Clay-P-OM) (Tisdall and Oades, 1982). Calcium ions are regarded as ion bridges forming microaggregates which result in a higher content of $\mathrm{Ca}^{2+}$ in residue microaggregates than in macroaggregates. The accumulation of organic carbon had a positive effect on aggregate stability in residues. Addition of organic waste had been considered as an effective method to improve related properties of bauxite residue and provide organic materials to plant growth. Jones et al. (2011) added organic waste into residue sand and found that organic materials improved aggregate stability of bauxite residue. Following natural processes, the microstructure of residue aggregates improved from a dense massive microstructure to a porous microstructure (Fig. 3 and Fig. 4).

\subsection{Effects on residue aggregate microstructure}

Soil structure is a key factor that influences various functions of soil and reflects the dynamic behavior of recycling and energy flow in soil (Barbosa et al., 2015). High resolution tomography facilities such as synchrotron-based $\mu$-CT have become available to permit quantitative studies of soil aggregate microstructure formation. The residue which had been stacked for 20 years supported plant 
growth and showed that it could be regarded as a soil-like medium. In this study, the indicator kriging method was used to determine aggregate microstructure and pore characterization in bauxite residue. Although pore-size distribution is one of the most important parameters, as it is expressed in terms of the frequency distribution of logarithmic effective radii, shape parameters such as throat area, path length and path tortuosity have been selected to describe the detailed aggregate microstructure in the residues (Schlüter et al., 2011).

The scanning images indicated that although the total number of pores in macro- or microaggregates decreased, the porosity (including macroporosity and mesoporosity) increased significantly compared to Z1 and Z2, whilst a greater quantity of large and long pores existed in Z3. The 3D pore systems for Z1 exhibited similar honeycomb patterns, while in Z2 and Z3, more continuous longer channels were found. The larger pore structure were beneficial to infiltration and substance exchanges between water, nutrients, gas and thermal conduction (Ayoubi et al., 2012). The accumulation of large pores resulted in a relatively loose physical structure which led to rapid moisture movement which effectively supply plant root absorption (Bui et al., 1989). Specific surface area of soil aggregates is a critical indicator of soil structure. The increase in specific surface area showed improvement in aggregate structure (Arthur et al., 2013). With increasing disposal age, specific surface area significantly increased, indicating that aggregate structure had improved.

The pore morphological parameters, such as pore throat area, path length, and tortuosity, revealed the aggregate structural differences between the different disposal ages. Z3 had a lower path number, but the longest paths and average path, compared to Z1 and Z2. The continuous longest paths are usually formed by plant roots or soil fauna which is beneficial to soil water flow (Peth et al., 2008). Compared to Z1 and Z2, the existence of plant roots may lead to longer pore paths in Z3. The residues (Z3) had a higher path tortuosity which showed that there was a large volume of irregular pores in residue aggregates. Zhou et al. (2013) found that soil aggregates had a higher path tortuosity with addition of organic waste, which was in agreement with our results. Natural regeneration significantly decreased the number of pore throats but increased their throat surface area which suggested that natural weathering processes may improve water, gas and nutrient fluxes in bauxite residue. The results demonstrate that shape parameters are also capable of differentiating macro- and microaggregate microstructures in bauxite residues.

All of these quantitative results, together with the $2 \mathrm{D}$ and $3 \mathrm{D}$ observations, have indicated that with increasing disposal age, and without human disturbance, both macro- and microaggregate structure, and aggregate stability and pore characterization have improved thereby supporting plant growth. These results confirm our hypothesis that natural regeneration may not only ameliorate physicochemical properties, but also promote residue aggregation and aggregate microstructure formation. Synchrotron-based X-ray micro-computed tomography and image analysis provided an improved understanding of aggregate microstructure and soil-formation process at the bauxite residue disposal area. Pore size distribution and shape parameters in residue aggregates may provide specific characterization of aggregation following natural regeneration. As soil formation is crucial for successful plant cover on the disposal area, high resolution tomography and image analysis may be regarded as an effective tool to evaluate aggregation and soil development processes for the rehabilitation of bauxite residue disposal areas. 


\section{Conclusions}

Natural regeneration ameliorated the physicochemical properties and aggregate stability of bauxite residues. With increasing disposal age, aggregate structure improved and became more stable. $\mathrm{Ca}^{2+}$ content increased whilst $\mathrm{Na}^{+}$content decreased on the surface of residue aggregates which indicated improvement in their structure. The total number of pores, number of interior pores, number of boundary pores, total number of throats, and total number of paths decreased significantly following natural regeneration, whilst porosity, specific surface area, average length of paths and average tortuosity of paths increased. The results indicated that long-term natural regeneration promoted aggregation and altered the three-dimensional microstructure of macro- and microaggregates. It verified our hypothesis that natural weathering processes may not only ameliorate the related physicochemical properties of bauxite residue, but also improve residue microstructure. Our future studies will investigate the improvement of microstructure and pore-size characterization in bauxite residue following addition of gypsum and organic waste.

\section{Acknowledgement}

Financial support from Environmental protection's special scientific research for Chinese public welfare industry (No. 201509048) and National Natural Science Foundation of China (No. 41371475) are gratefully acknowledged. The authors also acknowledge SSRF (Shanghai Synchrotron Radiation Facility) for supporting the use of the radiation source.

\section{References:}

Amézketa E. Soil Aggregate Stability: A review. Journal of Sustainable Agriculture 1999; 14: 83-151.

Annabi M, Le Bissonnais Y, Le Villio-Poitrenaud M, Houot S. Improvement of soil aggregate stability by repeated applications of organic amendments to a cultivated silty loam soil. Agriculture, Ecosystems \& Environment 2011; 144: $382-389$.

Arthur E, Tuller M, Moldrup P, Resurreccion AC, Meding MS, Kawamoto K, et al. Soil Specific Surface Area and Non-Singularity of Soil-Water Retention at Low Saturations. Soil Science Society of America Journal 2013; 77 : $43-53$.

Asensio V, Vega FA, Andrade ML, Covelo EF. Tree vegetation and waste amendments to improve the physical condition of copper mine soils. Chemosphere 2013; 90: 603-610.

Ayoubi S, Mokhtari Karchegani P, Mosaddeghi MR, Honarjoo N. Soil aggregation and organic carbon as affected by topography and land use change in western Iran. Soil and Tillage Research 2012; 121: 18-26.

Barbosa GMDC, Oliveira JFD, Miyazawa M, Ruiz DB, Filho JT. Aggregation and clay dispersion of an oxisol treated with swine and poultry manures. Soil and Tillage Research 2015; 146: 279-285.

Biederman LA, Boutton TW, Whisenant SG. Nematode community development early in ecological restoration: The role of organic amendments. Soil Biology \& Biochemistry 2008; 40: 2366-2374.

Bradshaw A. The use of natural processes in reclamation — advantages and difficulties. Landscape and Urban Planning 2000; 51 : 89-100.

Bronick CJ, Lal R. Soil structure and management: a review. Geoderma 2005; 124: 3-22.

Bui EN, Mermut AR, Santos MCD. Microscopic and Ultramicroscopic Porosity of an Oxisol as Determined by Image Analysis and Water Retention. Soil science Society of America Journal 1989; 53: 661-665.

Chauhan S and Ganguly A. Standardizing rehabilitation protocol using vegetation cover for bauxite waste (red mud) in eastern India. Ecological Engineering 2011; 37(3): 504-510.

Cheng M, Xiang Y, Xue Z, An S, Darboux F. Soil aggregation and intra-aggregate carbon fractions in relation to vegetation succession on the Loess Plateau, China. Catena 2015; 124: 77-84.

Courtney R, Harrington T, Byrne KA. Indicators of soil formation in restored bauxite residues. Ecological Engineering 2013; 58: 
63-68.

Courtney RG, Jordan SN, Harrington T. Physico-chemical changes in bauxite residue following application of spent mushroom compost and gypsum. Land Degradation \& Development 2009; 20(5): 572-581.

Courtney R and Kirwan L. Gypsum amendment of alkaline bauxite residue - Plant available aluminium and implications for grassland restoration. Ecological Engineering 2012; 42: 279-282.

Gelencsér A, Kováts N, Turóczi B, Rostási A, Hoffer A, Imre K, et al. The Red Mud Accident in Ajka (Hungary): Characterization and Potential Health Effects of Fugitive Dust. Environmental Science \& Technology 2011; 45: 1608-1615.

Gräfe M, Klauber C. Bauxite residue issues: IV. Old obstacles and new pathways for in situ residue bioremediation. Hydrometallurgy 2011; 108: 46-59.

Jiang C, Séquaris J, Vereecken H, Klumpp E. Effects of inorganic and organic anions on the stability of illite and quartz soil colloids in Na-, Ca- and mixed Na-Ca systems. Colloids and Surfaces A: Physicochemical and Engineering Aspects 2012; 415: $134-141$.

John B, Yamashita T, Ludwig B, Flessa H. Storage of organic carbon in aggregate and density fractions of silty soils under different types of land use. Geoderma 2005; 128: 63-79.

Johnston M, Clark MW, McMahon P, Ward N. Alkalinity conversion of bauxite refinery residues by neutralization. Journal of Hazardous Materials 2010; 182: 710-715.

Jones BEH, Haynes RJ. Bauxite Processing Residue: A Critical Review of Its Formation, Properties, Storage, and Revegetation. Critical Reviews in Environmental Science and Technology 2011; 41: 271-315.

Jones BEH, Haynes RJ, Phillips IR. Influence of organic waste and residue mud additions on chemical, physical and microbial properties of bauxite residue sand. Environmental Science and Pollution Research 2011; 18: 199-211.

Karami A, Homaee M, Afzalinia S, Ruhipour H, Basirat S. Organic resource management: Impacts on soil aggregate stability and other soil physico-chemical properties. Agriculture, Ecosystems \& Environment 2012; 148: 22-28.

Kaur N, Phillips I, Fey MV. Amelioration of bauxite residue sand by intermittent additions of nitrogen fertiliser and leaching fractions: The effect on growth of kikuyu grass and fate of applied nutrients. Science of the Total Environment 2016; 550: $362-371$.

Lindquist WB, Venkatarangan A, Dunsmuir J, Wong TF. Pore and throat size distributions measured from synchrotron X-ray tomographic images of Fontainebleau sandstones. Journal of Geophysical Research Solid Earth 2000; 105: $21509-21527$.

Liu WC, Chen XQ, Li WX, Yu YF, Yan K. Environmental assessment, management and utilization of red mud in China. Journal of Cleaner Production 2014; 84: 606-610.

Ma R, Cai C, Li Z, Wang J, Xiao T, Peng G, et al. Evaluation of soil aggregate microstructure and stability under wetting and drying cycles in two Ultisols using synchrotron-based X-ray micro-computed tomography. Soil and Tillage Research 2015; 149: 1-11.

Newson T, Dyer T, Adam C, Sharp S. Effect of Structure on the Geotechnical Properties of Bauxite Residue. Journal of Geotechnical and Geoenvironmental Engineering 2006; 132: 143 - 151.

Oh W, Lindquist WB. Image Thresholding by Indicator Kriging. IEEE Transactions on Pattern Analysis \& Machine Intelligence 1999; 21: 590-602.

Peth S, Horn R, Beckmann F, Donath T, Smucker AJM, Fischer J. Three-Dimensional Quantification of Intra-Aggregate Pore-Space Features using Synchrotron-Radiation-Based Microtomography. Soil Science Society of America Journal 2008; 72: $897-907$

Power G, Gräfe M, Klauber C. Bauxite residue issues: I. current management, disposal and storage practices. Hydrometallurgy $2011 ; 108(1-2): 33-45$.

Renforth P, Mayes WM, Jarvis AP, Burke IT, Manning DAC, Gruiz K. Contaminant mobility and carbon sequestration downstream of the Ajka (Hungary) red mud spill: The effects of gypsum dosing. Science of the Total Environment 2012; s 421-422: 253-259. 
Ruyters S, Mertens J, Vassilieva E, Dehandschutter B, Poffijn A, Smolders E. The Red Mud Accident in Ajka (Hungary): Plant Toxicity and Trace Metal Bioavailability in Red Mud Contaminated Soil. Environmental Science \& Technology 2011; 45: 1616-1622.

Santini TC, Fey MV. Spontaneous Vegetation Encroachment upon Bauxite Residue (Red Mud) As an Indicator and Facilitator of In Situ Remediation Processes. Environmental Science \& Technology 2013; 47: 12089-12096.

Schlüter S, Weller U, Vogel HJ. Soil-structure development including seasonal dynamics in a long-term fertilization experiment. Journal of Plant Nutrition \& Soil Science 2011; 174: 395-403.

Schmid B, Schindelin J, Cardona A, Longair M, Heisenberg M. A high-level 3D visualization API for Java and ImageJ. Bmc Bioinformatics 2010; 11: 1-7.

Six J, Paustian K. Aggregate-associated soil organic matter as an ecosystem property and a measurement tool. Soil Biology and Biochemistry 2014; 68: A4-A9.

Tisdall JM, Oades JM. Organic matter and water - stable aggregates in soils. European Journal of Soil Science 1982; 33: 141-163.

Udawatta RP, Anderson SH, Gantzer CJ, Garrett HE. Influence of Prairie Restoration on CT-Measured Soil Pore Characteristics. Journal of Environmental Quality 2008; 37: 219-28.

Wu C, Zou Q, Xue SG, Pan WS, Huang L, Hartley W, et al. The effect of silicon on iron plaque formation and arsenic accumulation in rice genotypes with different radial oxygen loss (ROL). Environmental Pollution 2016; 212: 27-33.

Xue SG, Zhu F, Kong XF, Wu C, Huang L, Huang N, et al. A review of the characterization and revegetation of bauxite residues (Red mud). Environmental Science and Pollution Research 2016; 23: 1120-1132.

Yilmaz E. Assessment of the role of agricultural wastes in aggregate formation and their stability. Journal of Environmental Management 2014; 144: 93-100.

Zhou H, Peng XH, Perfect E, Xiao TQ, Peng GY. Effects of organic and inorganic fertilization on soil aggregation in an Ultisol as characterized by synchrotron based X-ray micro-computed tomography. Geoderma 2013; 195-196: 23-30.

Zhou H, Peng X, Peth S, Xiao TQ. Effects of vegetation restoration on soil aggregate microstructure quantified with synchrotron-based micro-computed tomography. Soil and Tillage Research 2012; 124: 17-23.

Zhu F, Xue SG, Hartley W, Huang L, Wu C, Li XF. Novel predictors of soil genesis following natural weathering processes of bauxite residues. Environmental Science and Pollution Research 2016; 23: 2856-2863.

Zhu F, Zhou JY, Xue SG, Hartley W, Wu C, Guo Y. Aging of bauxite residue in association of regeneration: a comparison of methods to determine aggregate stability \& erosion resistance. Ecological Engineering 2016; 92: 47-54. 